\title{
Pastores en el 'Quijote'
}

\author{
FRANCISCO LÓPEZ EsTRADA*
}

\section{INTRODUCCIÓN}

El título de este artículo no puede ser más sencillo. Se trata de saber qué relación se establece entre los pastores, tipo social que tiene una extensa e intensa poética desde los principios de la literatura europea, y en la española como parte de la misma, con el Quijote, el libro que escribió Cervantes, y que es una determinada obra literaria que pertenece a un concreto género, que es el de la novela, desarrollado en el curso de los Siglos de Oro. En su caso, Cervantes en su libro interpreta la transformación de un hombre de una época determinada, la suya propia, en un espacio de su vida por causa de una locura transitoria, causada por la lectura desorbitada de los libros de caballerías. Este es, pues, el contenido que se interpreta formando, en lo que cabe, una unidad de exposición en la historia literaria con la comparación de los libros de pastores, un género del mismo periodo, y el Quijote, la obra de un autor y época conocidos.

\section{LOS PASTORES Y SU ASPECTO LITERARIO EN RELACIÓN CON EL "QUIJOTE"}

"Pastores" es el título más común de los que se ocupan de cuidar y guardar el ganado; su labor tiene una larga historia social en los pueblos, y es una de las actividades humanas necesarias para su desarrollo. En la constitución de este grupo social, que en principio ellos no forman, sino que viven aislados o en

* Profesor emérito de la Universidad Complutense de Madrid. 
poca compañía, se da la circunstancia de que se valen de usos artísticos de carácter literario o musical. Así ha ocurrido en la literatura española (como en otras), en la cual, en su historia, desde sus orígenes, hay un capítulo abundante de la literatura llamada "pastoril", y en cada época tiene manifestaciones de la misma con cualidades diversas. Como aquí se trata de relacionar estas manifestaciones con el Quijote, si bien este libro de Cervantes está relacionado en primer término con el artificio social de la caballería y sus manifestaciones literarias, creo que el que le sigue en importancia es el de la literatura pastoril ${ }^{1}$. La diversidad que cabe en el tratamiento de los asuntos pastoriles es uno de los motivos de este estudio.

Y creo que conviene tratar, en primer lugar, de la aplicación de los términos persona y personaje a la función literaria del pastor que aparece en la obra literaria, aquí en el Quijote. El término persona en el latín de la Antigüedad literaria es 'máscara del actor', lo que se oye en el teatro y suena a través de esa máscara, y por extensión la figura teatral reconocible por su vestimenta y gesticulación, además de por las palabras que diga. Esta acepción es posible que la conocieran algunos escritores de los Siglos de Oro que seguían de cerca los textos latinos. En la traducción del Asno de Oro de Apuleyo de 1543, se usa la palabra para designar la representación que se ha conseguido, aunque sea mediante un disfraz del actor. Se trata de una procesión de disfrazados, y se dice de unos de ellos: "tras deste, otro con su bordón, esclauina y alpargatas y con barbas de cabrón, representaua y fingía de persona de philósopho" 2 . O sea que la representación era fingida, "cómica" pero reconocible en su calidad de tal filósofo. En su significación plena designa la figura que se trata de representar con todas sus implicaciones. Covarrubias, en su diccionario del castellano, siente aún tal respeto por la palabra, que la define en latín: "Según los filósofos, persona est naturae rationalis individua substantia."3. El Tesoro de la Lengua la entiende como léxico propio de filósofos, y con ello quiere decir personas cultas, amantes de la sabiduría, y así lo acreditan sus antecedentes ${ }^{4}$. Sin embargo, la palabra se fue generalizando, conservando una significación de dignidad humana, y se aplicó incluso a los protagonistas de la literatura, hasta a las formas menos elaboradas de ella, como es el cuento: "A

1. Puede notarse esta afluencia en los estudios que por alguna razón tratan de la diversidad de materias presentes en el libro de Cervantes, como es el de Augustin Redondo, "Acercamiento al Quijote desde una perspectiva histórico-social”, Cervantes, Centro de Estudios Cervantinos, Alcalá de Henares, 1995, págs. 257-293. También por referirse a la misma época, cito el de Dominick FINELLO, “The Pastoral Novel and Spains' Literary Culture of the Early Seventeenth Century", A Celebration of Brooklin Hispanism, Juan de la Cuesta, 2004, págs. 77-94.

2. Orígenes de la novela, IV, (Apuleyo, El Asno de Oro y otras), Ed. Nueva Biblioteca de Autores Españoles, Madrid, Casa Editorial Bailly/Baillére, 1915, 21, cap. II, pág. 95.

3. Sebastián de Covarrubias, Tesoro de la lengua castellana o española, Barcelona, Editorial Alta Fulla, Edición de Martín de Riquer. 1989, pág. 866.

4. José Jesús de Bustos Tovar, Contribución al cultismo léxico medieval, Anejo XXVIII del Boletín de la Real Academia Española, Madrid, 1974, págs. 612. 
estos dos caualleros moços, cómo quien han de ser las principales personas deste cuento..."5. Y otras veces se vacía de sentido dentro del sentido novelesco de la obra: "Leuantáronse los dos y quando abrieron no hallaron persona, ni hallaron quien les auía dado el aviso." 6 , en donde no hay otra referencia que la calidad humana de los individuos referidos.

"Personaje" se aplica a la figura del teatro, y se entiende que a la "persona" que es el actor, se une la figura ficticia que ha de interpretar, lo que se llamaría el "papel de comedia" que se ha de representar en la obra. Y aún hay otra palabra, poco usada, que se une a estas:"personado". He aquí una cita del Criticón de Gracián: “...cuando [se refiere a Dante] habiéndose disfrazado en uno de los días carnavales y mandándole el Médicis, su gran patrón y Mecenas, para poderle conocer entre tanta multitud de personados..."7. La variante "presonaje" que usa Sancho por error, está causado por desconocer la palabra culta; cuando se refieren a la primera Parte en el comienzo de la segunda de la obra, Sancho, don Quijote y el Bachiller, dice Sancho: "Y de mí -dijo Sancho-, que también dicen que soy yo uno de los principales presonajes della". Y Sansón Carrasco le corrige: "Personajes que no presonajes"8. Por eso es Bachiller, y conoce el término y su problemática significativa.

Cuando Cervantes escribe el Quijote, su intuición creadora le inclina a jugar con estas palabras que su significación depende de su uso condicionado. Y la misma denominación de su "héroe" es uno de estos juegos que he estudiado basándome en una obra que creo que es de importancia para comprender su creación, en una traducción del mencionado Asno de Oro de Apuleyo, donde hay tantas intuiciones "novelescas". El uso del término quixote en ella, en la traducción de Diego López de Cortegana, un erasmista de principios del siglo XVI, respetable arcediano y canónigo de Sevilla, en su sentido recto de pieza de la armadura, que sale en unos juego de disfraces, me parece un anuncio de su uso "cómico" tan acertado en Cervantes?.

Es hora de acercarse al trato de la materia literaria pastoril en relación con el Quijote. En la amplitud de referencias que se hacen en el libro, he dicho que las relativas a los pastores me parecen importantes en el conjunto de la obra. La figura del pastor aparece en el Quijote a través de las diversas acepciones que maneja Cervantes. Y esto está en relación con la primera obra que

5. Carlos Fernández Gómez, Vocabulario de Cervantes, Real Academia Española, MCMLXII, Ilustre fregona, pág. 788. Como este libro se ha de citar otras veces, lo indicaré sólo como Voc. Cervantes, 1952, la página en que se encuentra la referencia y la obra de que se trata, excepto si la cita es del Quijote porque entonces pertenece a la edición: Miguel de CERvantes, Don Quijote de la Mancha, edición del Instituto Cervantes, Barcelona, Crítica, 1998, I, texto, y II, volumen complementario.

6. Voc. Cervantes, 1952, pág. 788, Quijote.

7. Baltasar Gracián, Obras Completas, Madrid, M. Aguilar, 1944, pág. 795

8. Miguel de Cervantes, Quijote, II, cap. III, pág. 650.

9. Francisco LóPez Estrada, "Quixotes en el Apuleyo castellano", Siglos dorados. Homenaje a Augustin Redondo, II, Madrid, Editorial Castalia, 2004, págs. 797-805. 
escribió como autor ${ }^{10}$. Por tanto, Cervantes conoce el libro de pastores como creador literario, en sus dos aspectos de prosa y verso. Y esto antes que él se plantee escribir la novela del Quijote con su diversidad argumental y su dependencia con los libros de caballerías. Y Cervantes no acaba este libro de la Galatea porque, (según confiesa en el prólogo del Persiles y Sigismunda, en la que es la última de sus cartas públicas, escrita como prólogo, a don Pedro Fernández de Castro, Conde de Lemos), sería "milagro" según el estado moribundo en que se encontraba, que acabara la que había sido su primera obra; según su voluntad manifestada el 19 de abril de 1616, aún tenía la intención de hacerlo, pues no eran "ciertas reliquia y assomos" de una obra, sino precisamente el "fin" de la Galatea. O sea que ya le faltaba poco para acabarla, y la tenía en gran parte escrita. Si tenemos en cuenta que el primero de febrero de 1584 Lucas Gracián Dantisco escribe en la Aprobación de los preliminares de la Galatea lo que es el mejor elogio de la obra: "tratado apacible y de mucho ingenio, sin perjuicio de nadie, así la prosa como el verso; antes por ser libro provechoso, de muy casto estilo, buen romance y galana invención, sin tener cosa malsonante, deshonesta, ni contraria a buenas costumbres". Eso dicho de una obra pastoril como la Galatea, la hace propia de la lectura femenina, lo mismo que la literatura caballeresca es la más adecuada para la lectura masculina, si bien algunas mujeres declararon su afición por ella. La calidad de lectores o lectoras se preanuncia en las obras, y es un factor que influiría en los autores de las mismas y que favorecería su venta según los impresores y libreros. La gran literatura pastoril se hallaba en punto de decadencia, y era necesario renovar la relación con el público lector que compraba las obras. Los libros de pastores eran una manifestación suma de la literatura pastoril puesto que su entidad era eso, un "libro", y no composiciones sueltas o reunidas en un conjunto.

El Quijote comienza en un hombre que cambia su persona de Alonso Quijano, el "bueno", y que, por la lectura excesiva de los libros de caballerías, acabó perdiendo el juicio, y una de las manifestaciones de su locura es elegir el nombre que usa en el libro "don Quijote de la Mancha"11, y acomodar todo lo que ve a lo que había leído e interpretar esos datos como experiencia. La obra comienza como si fuese una "novela" de las Ejemplares, hasta el capítulo VI, en que podía haber terminado la obra con la restitución del juicio a don Alonso, de una forma parecida al mismo Quijote. Sin embargo, Cervantes se dio cuenta de que la creación del personaje daba para mucho más, y la novela corta se podía convertir en un libro, y aún de

10. Las citas de la Galatea proceden de: Miguel de Cervantes, La Galatea, Edición de Francisco López Estrada y María Teresa García-Berdoy, Cátedra, Letras Hispánicas, 1995; véase la bibliografía en las páginas 123-143.

11. Dice así el personaje principal de la obra al final de la misma, y cerrándola con ello: "Dadme albricias, buenos señores, de que ya no soy don Quijote de la Mancha, sino Alonso Quijano, a quien mis costumbres me dieron el renombre de "bueno"”, Quijote, II, Cap. LXXIIII, pág. 1217. 
dos tomos. El escrutinio que el cura y el barbero hicieron de la biblioteca de Alonso Quijano fue una de las claves.

En el Quijote se cita a un hidalgo, don Diego de Miranda, que también tiene una biblioteca. Es un encuentro de paso por los caminos seguidos por don Quijote. Don Diego acredita su buena condición social por lo bien vestido que va y su buena habla. Entablan conversación, y don Quijote declara quién es y qué se propone. Y don Diego le dice que es un hidalgo, y en esto que encuentran un carro con unos leones, y don Quijote tiene allí su aventura, de la que sale con fortuna. Don Diego invita a su casa a don Quijote y le presenta a su señora y a su hijo. Las circunstancias de la familia manifiestan ser las de propias de un caballero labrador y rico. Y describe su biblioteca: "Tengo hasta seis docenas de libros, cuales de romance y cuales de latín; de historia algunos y de devoción otros; los de caballerías aún no han entrado por los umbrales de mis puertas"12. En la revisión que habían hecho los amigos de Alonso Quijano, se trataba de quemar los libros de caballerías que habían causado el daño de la locura en su vecino, y con que desapareciesen de su biblioteca, se obtenía el remedio. Se concedía el perdón al Amadís, pero no a los demás, salvo a alguno, como a la traducción del Tirante el Blanco. Los amigos de don Alonso, examinados y castigados los de caballerías, observaron que quedaban en la biblioteca unos "pequeños libros", que dijo el cura que "no deben ser de caballerías"13. Y, en efecto, comienza la mención de los libros pastoriles, y el primero es la Diana de Montemayor, y tras él se menciona la de Alonso Pérez, condenada también al fuego por su mala calidad literaria, y el libro de Gil Polo, al que se otorga un elogio desmesurado. Se citan Los diez libros de Fortuna de amor de Lofraso, y otros tres, que se condenan al fuego, El Pastor de Iberia, Ninfas de Henares y Desengaño de celos, de Bernardo de la Vega, Bernardo González de Bobadilla y Bartolomé López de Enciso, respectivamente. El Pastor de Fílida de Gálvez de Montalvo sale bien parado, aunque dicen que no es pastor, sino discreto cortesano. Después de mencionar el Cancionero de López Maldonado, Cervantes se atreve a citar su propia Galatea, de la que dice él mismo que acaso la segunda parte prometa y puede que mejorara la primera. $\mathrm{Y}$ después se citan tres poemas épicos, con un elogio personal de Las lágrimas de Angélica, de Barahona de Soto. La sobrina de don Alonso insinúa que acaso la locura caballeresca fuese seguida de la pastoril, y con esto anuncia lo que será el fin de su tío cuando al término del libro, en la Segunda Parte, cap. LXVII, se expone "la resolución que tomó don Quijote de hacerse pastor y seguir la vida del campo". Así la conversión en pastor es la vía del fin de Don Quijote, y los pastores enlazan con la caballería por causa del prestigio de los dos géneros en el cultivo literario, indicio que era de los más conocidos entre los lectores de libros de entretenimiento.

12. Quijote, II, cap.XVI, pág. 754.

13. Quijote, I, Cap. VI, pág. 83-87. 


\section{LA DIVERSIDAD DEL GÉNERO PASTORIL EN EL CURSO DEL "QUIJOTE"}

Por tanto, quien leyese el Quijote en tiempos inmediatos a Cervantes, desde 1605 y 1615 , es posible que también lo hubiese hecho con los libros pastoriles, al menos siquiera con algunos de ellos. No se trata de crecer los méritos literarios de los libros, sino de su relativa aceptación por parte de los lectores. La Diana de Montemayor se había publicado alrededor de veinte y cinco veces. Y Cervantes había colaborado a esta difusión de semejantes obras con la primera Parte de la Galatea en 1585, su primer libro publicado. Cervantes sabe que con los libros de caballerías, en franco declive en el gusto general del público lector, está él dando lanzadas a un cuerpo literario casi muerto. En la apreciación actual, esto ocurre al revés. Hoy somos contados los que leemos la Diana o la Galatea. Y muchos los que lo hacen con el Quijote, porque el aprecio del libro de Cervantes es resultado de varios siglos de progresivo reconocimiento y aprecio literarios. Ahora trataremos de encontrar las relaciones que se pueden establecer entre la literatura pastoril de la época y la creación del Quijote, en tanto que aquella intervino en este como un elemento activo y partícipe en su formación.

\section{SANCHO, PASTOR}

Por de pronto, hay que asegurar algo patente y que apenas ha sido tenido en cuenta: el propio Sancho, muy al principio del Quijote, confiesa que ha sido pastor y que sabe medir el tiempo como lo hacen los pastores por la noche. Esto ocurre cuando el estruendo que ocasionan seis mazos de batán, movidos por el agua de un río, y asustan al caballero y al escudero. Sancho pide a su señor que no acometa la aventura de enfrentarse con la causa de tan misterioso ruido, y le dice entre otras cosas: "Por un solo Dios, señor mío, que non se me faga tal desaguisado, y ya que del todo no quiera vuestra merced desistir de acometer este fecho, dilátelo, a lo menos, hasta la mañana; que, a lo que a mí me muestra la ciencia que aprendí cuando era pastor, no debe haber desde aquí al alba tres horas..."14. Y en esta ocasión, Sancho habla según la manera de don Quijote, atosigado por el miedo. Y es aquí donde Sancho, poco después, narra el cuento de los amores de Lope Ruiz con Torralba, y emplea un estilo reiterativo en la designación del oficio pastoril: "Digo, pues -prosiguió Sancho- que en un lugar de Estremadura había un pastor cabrerizo, quiero decir que guardaba cabras, el cual pastor o cabrerizo, como digo en mi cuento..."15. Sancho emplea la denominación conveniente referente a los pastores. Y esto lo repite otras veces. Cuando repasa los merecimientos para ser gobernador,

14. Quijote, I, cap. XX, pág. 210.

15. Quijote, I, cap. XX, pág.212.

ANALES CERVANTINOS, VOL. XXXVII, PP. 15-32, 2005. ISSN: 0569-9878 
recuerda "la consideración de haber guardado puercos en tu tierra". Y responde Sancho: "Así es la verdad, [...] pero fue cuando muchacho; pero después, algo hombrecillo, gansos fueron los que guardé, que no puercos"16. Hay más citas, y Teresa Panza cree que sólo vale para "gobernar un hato de cabras"17. Sancho, que ya ha sido suficientemente estudiado como figura folklórica y carnavalesca, aparece aquí como pastor que conoce por experiencia el aspecto del cielo nocturno con el movimiento de las estrellas. Un aspecto de la condición cómica de Sancho se descubre en esta perspectiva pastoril que recuerda de cuando ejercía como pastor.

No nos queda ninguna pieza pastoril en el teatro de Cervantes. El estudio de La casa de los celos y selvas de Ardenia muestra un texto en que se mezclan las concepciones pastoril y caballeresca, y aparecen en escena Lauso, Corinto y Rústico, unos pastores entre las figuras épicas representación de personajes morales. Es una obra primitiva y confusa, y ya apunta la diversidad de personajes de origen distinto.

\section{GARCILASO EN EL “QUiJOTE”}

Cuando don Quijote tiene que esforzarse en interpretar los datos "reales" de la imaginada entrevista con Dulcinea que le cuenta Sancho, sólo se le ocurre recordar con pormenor los versos de la Égloga III de Garcilaso, y rehacer él, desde su perspectiva literaria, la zafiedad de Sancho. Y dice: "Mal se te acuerdan a ti, oh Sancho, aquellos versos de nuestro poeta donde nos pinta las labores que hacían allá en sus moradas de cristal aquellas cuatro ninfas que del Tajo amado sacaron las cabezas, y se sentaron a labrar en el prado verde aquellas ricas telas que allí el ingenioso poeta nos describe, que todas eran de oro, sirgo y perlas contestas y tejidas. Y desta manera debía de ser el de mi señora cuando tú la viste..."18. Don Quijote recordaba de memoria la Égloga de Garcilaso y la vertía en su conversación en prosa para afirmar con ella la imaginada imagen de su señora. Cervantes con esto prosigue el entrelazamiento genérico que se encuentra en la invención del Quijote. Cervantes, como tantos escritores de la época, reunía en su personaje el conocimiento de la lírica de Garcilaso, resorte efectivo en la constitución del libro.

\section{DULCINEA, NOMBRE PASTORIL}

En la voluntad heroica de don Quijote, cuando se trata de pasar de la persona de ficción que ella representa, Aldonza Lorenzo, a su conversión en personaje, se transforma, en la alegre euforia de la recién estrenada locura, en Dulcinea. Y a

16. Quijote, II, cap. XLII, pág. 970.

17. Quijote, II, cap. LXII, pág. 1056.

18. Quijote, II, cap.VIII, pág. 688. 
este nombre le añade la mención "del Toboso", nombre de su aldea, que es topónimo castellano que da raíces geográficas al título. El nombre completo le pareció "músico y peregrino y significativo"19. Pues bien, este nombre no procede de los libros de caballerías, sino que gana favor en la línea de los pastoriles, acercándolo a la realidad cotidiana de la aldea.

\section{El DISCURSO A LA EDAD DE ORO, DIRIGIDO A LOS CABREROS}

La primera transfusión pastoril aparece pronto en el cuerpo de la obra. Ocurre cuando el encuentro de la pareja don Quijote y Sancho con unos cabreros. Es el contraste más elemental que cabe proporcionar al lector: el de la realidad social del mundo pastoril y la otra realidad imaginada del mismo en la literatura. Entre las distintas clases de pastores la literatura reconoce, como hemos visto, la de los "rústicos". Y entre ellos estaban los de cabras, que viven en unas chozas, y ofrecen a don Quijote y Sancho su rústica mesa. En agradecimiento a la bondadosa hospitalidad de estos pastores, don Quijote pronuncia el discurso de la Edad de $\mathrm{Oro}^{20}$. Es una pieza oratoria redonda, recortable en el curso de la obra, fuera de lugar, como un repentino juego académico. Ellos, los pastores, no comprenden nada, porque son cabreros, los más humildes de los pastores. Don Quijote tiene el mejor público que podría esperar. Las palabras siguen un curso oratorio, músico (obsérvese el valor melódico de la frase), y peregrino por las circunstancias de su emisión, pues ni los cabreros (ni Sancho) comprenden nada, pues sobrepasa su nivel intelectual. Pero el efecto está logrado.

\section{Los CABreros DE SierRa Morena}

El caso de los pastores de Sierra Morena se complica más porque Cervantes enlaza dos hilos en este espacio de trama: Don Quijote, ejerciendo de loco enamorado, y Cardenio, haciendo otro tanto, cada cual a su manera y a la sombra de los patrones respectivos. Cardenio es un personaje que se define a sí mismo así: "Mi nombre es Cardenio; mi patria, una de las mejores de esta Andalucía; mi linaje noble; mis padres, ricos; mi desventura, tanta, que la deben de haber llorado mis padres, y sentido mi linaje, sin poderla aliviar con su riqueza, que para remediar desdichas del cielo, poco suelen valer los bienes de fortuna"21. Don Quijote es la locura por amor, imitación de las lecturas de Amadís, y Cardenio enloquece por amor, que es real, dentro de la ficción novelesca, con resonancias ariostescas. La razón de Cardenio sufre un eclipse

19. Quijote, I, cap.I, pág. 44.

20. Quijote, I, cap.XI, pág. 121-123.

21. Quijote, I, cap. XXIV, pág. 263.

ANALES CERVANTINOS, VOL. XXXVII, PP. 15-32, 2005. ISSN: 0569-9878 
y se comporta como un loco. El caballero explica su desgracia amorosa que lo alejó de Luscinda, su amada, y se refugió en la Sierra, donde entonces se hallaba, como el mismo dice: "...tan desmedrado y flaco, que hago mil locuras" 22 . La intervención de otra pareja, Fernando y Dorotea, hacen más compleja esta parte del Quijote, y Cervantes se da cuenta de la gravedad de esta desviación que desequilibra un tanto la línea argumental. En el comienzo del capítulo XXVIII de la Primera Parte (que es el comienzo de la Cuarta Parte de una división inicial del libro), el autor dice esto en elogio de la obra, que su edad (es decir, la época en que se escribe) necesita "...no sólo de la dulzura de su verdadera historia, sino de los cuentos y episodios della, que, en parte, no son menos agradables y artificiosos y verdaderos que la misma historia" 23 . La verdadera historia (la de don Quijote) necesita de los episodios, y aquí acaso Cervantes enuncia este consejo. Y aquí en esta parte, por si alguien estima que se ha excedido, avisa de la dicha manera. Y esto importa también para el fin de este artículo, que es el poner de relieve la relación entre la literatura pastoril y el Quijote.

\section{EL ROMANCE DEL CABRERO ANTONIO}

No todos los cabreros son iguales en su ignorancia. Cervantes escribe de uno de ellos que es: “...un zagal muy entendido y muy enamorado, y que, sobre todo, sabe leer y escrebir y es músico de un rabel, que no hay más que desear." ${ }^{24}$ Los pastores le dicen a Antonio, que así se llama este cabrero que sabe de letras y música, que cante para que se vea cuál es su arte. Antes hace saber que el que compuso la poesía fue un tío suyo, clérigo beneficiado, y que el romance ha parecido muy bien en el pueblo. He aquí una confluencia literaria en que un clérigo escribe de amores para un pastor que es un cabrero.

\section{El EPISODIO DE MARCELA Y GRISÓSTOMO}

Y es precisamente aquí, en este espacio de los cabreros, que el Quijote enlaza con un gran episodio - grande en extensión y en sentido- en que la burla de los libros de caballerías se cambia por un relato propio de un libro de pastores. Inicia el nuevo caso un mozo que llega del pueblo con la noticia que Grisóstomo ha muerto de amor por Marcela: “....aquel famoso pastor estudiante llamado Grisóstomo, y se murmura que ha muerto de amores por aquella endiablada moza de Marcela, la hija de Guillermo, el rico, aquella que anda en hábito de pastora por esos andurriales". ${ }^{25}$ Como Don Quijote es por naturaleza curioso y

22. Quijote, I, cap. XXVII, pág. 315.

23. Quijote, I, cap. XXVIII, pág.317.

24. Quijote, I, cap. XI, pág. 124.

25. Quijote, I, cap. XII, pág. 128. 
receptivo, pregunta sobre el caso y se une a los que quieren saber sobre aque1lo. Observemos que Cervantes prepara la nueva narración: el pastor es estudiante; se llama Grisóstomo, vulgarización de Crisóstomo, boca de oro, nombre extraño a los pastores, Marcela es hija de alguien, rico, con lo que una nota social se añade al relato. Ella "anda en hábito de pastora", y no dice que lo sea por necesidad, sino por su gusto. Los lectores ya están avisados; no pueden llamarse a engaño. La persona cambia en personaje. La narración pastoril de los cabreros pasa a ser propia de la hidalguía burguesa. Hay un coro de espectadores, entre los que se cuenta Don Quijote, que no participan en el caso, pero se sienten atraídos por lo que allí ocurre.

Pronto tienen ocasión de encontrar el entierro de Grisóstomo. Por Vivaldo conocen más noticias del suceso. Incluso los presentes tienen interés en conocer la última Canción desesperada que escribió Grisóstomo ${ }^{26}$, lo mismo que pasa en los libros de pastores. Este es un caso en que el pastor principal muere, algo no frecuente en tales libros. Esto se encuentra también en la Galatea, el primer libro de Cervantes, de 1585, donde ocurre el caso trágico del asesinato del pastor Erasto por el pastor Carino. Grisóstomo era un pastor de la casa de un labrador rico, con bienes abundantes, y Marcela era hija de otro, aún más rico. Recuérdese que Cervantes notó que "iba en hábito de pastora", y esto significa que ha tomado un hábito civil para poner de manifiesto que se ha comprometido con un orden de vida en el que la literatura ordena el trato humano y social. Esto no significa leer las Dianas y libros semejantes, como era común entre las mujeres de la época, sino practicar lo que allí se cuenta como un sistema de relaciones humanas. Y si don Alonso, el hidalgo manchego, quería hacer lo mismo con los libros de caballerías, resulta que Cervantes inventa un camino semejante por la vía pastoril con las consecuencias trágicas de la muerte. Don Alonso "iba en hábito de caballero andante", y por eso se convierte en Don Quijote. Y como tal se encuentra entre los espectadores que, poco a poco, se enteran del caso que allí ocurre, y don Quijote se da cuenta y presiente que lo que allí acontece tiene que ver con su manera de entender la vida desde que recibió la iluminación caballeresca.

$\mathrm{Y}$ en este punto de la tensión narrativa, Marcela aparece ante la comitiva fúnebre, y lo hace de una manera espectacular. Y Cervantes nos lo cuenta con sorprendente acierto, Ellos ven: “...una maravillosa visión -que tal parecía ellaque improvisamente se les ofreció a los ojos; y fue que por cima de la peña donde se cavaba la sepultura, pareció la pastora Marcela, que pasaba a su fama su hermosura." 27 Esto es algo asombroso en las tierras manchegas, en donde se leen versos de pasiones humanas en vez de responsos. Don Quijote, como los demás, sigue los hechos pasivamente. La lanza del caballero está quieta. Está con Grisóstomo como ante un héroe que ha caído por sus mismos ideales, pero también está con Marcela cuando justifica su comportamiento. Dice ella: "Yo

26. Quijote, I, cap.XIV, pág. 146-151.

27. Quijote, I, cap. XIV, pág. 152. 
nací libre y para poder vivir libre, escogí la soledad de los campos. Los árboles destas montañas son mi compañía, las claras aguas destos arroyos, mis espejos; con los árboles y con las aguas comunico mis pensamientos y hermosura. Fuego soy apartado y espada puesta lejos. A los que he enamorado con la vista, he desengañado con las palabras. Y si los deseos se sustentan con esperanzas, no habiendo yo dado alguna a Grisóstomo ni a otro alguno, en fin de ninguno dellos, bien se puede decir que antes lo mató su porfía que mi crueldad". 28

La vida tiene para ella un sentido: la libertad, que aquí defiende por encima del amor. Es la inevitable tragedia de la relación humana, pretendida pero no lograda. Cervantes no inventa nada al presentar así a Marcela. Recoge una posición que también ocurre en el amor cortés provenzal, un tópico general de la lírica. Aquí el tópico se enlaza con el de la libertad de la persona, cuestión que alcanza la teología y, después de su inmersión literaria, puede acabar en la sociología. Cervantes lo plantea hasta sus últimas consecuencias, pues su amante muere por causa del mismo amor, pero otros no lo hacen, y todo queda en un tópico expresivo. Grisóstomo escribe versos que él llama "desesperados" (que indican que perdió la "esperanza", virtud cristiana fundamental), y por eso se le entierra fuera del cementerio, en el campo.

Ella se justifica ante todos. La causante de la tragedia fue la condición humana, aplicada a un caso de amor. Y cuando ha dicho todo lo que conviene, ella se retira de allí. Vuelve al monte a sus ejercicios pastoriles, y algunos quieren seguirla. Entonces se dispara el resorte caballeresco de don Quijote y pasa a ser de espectador a protagonista en el suceso: "Ninguna persona, de cualquier estado y condición que sea, se atreva a seguir a la hermosa Marcela, so pena de caer en la furiosa indignación mía"29. El caballero andante ampara la libertad, palabra que ha movido la intervención de don Quijote. No se trata, pues, de una farsa, si se muere y en hábito pastoril.

El episodio es breve, y está entretejido en lo que le ocurre, yendo por los caminos, a don Quijote, pero es ilustrativo de la manera como la materia pastoril ha penetrado en el libro de Cervantes.

\section{LO PASTORIL COMO FARSA FESTIVA EN EL 'QUIJOTE'}

El caso de Grisóstomo y Marcela es extremado, "peregrino", como le gusta decir a Cervantes. Más frecuente era que la literatura pastoril se convirtiera en espectáculo propio para fiestas cortesanas, de mayor o menor grado. Don Quijote se encuentra con uno de estos festejos. Esto ocurre cuando yendo por el camino se encuentran con unas pastoras que dejan atónitos al caballero y al escudero. Lo cuenta así Cervantes; “...al improviso se le ofrecieron delante, 
saliendo de entre unos árboles, dos hermosísimas pastoras; a lo menos vertidas como pastoras, sino que los pellicos y sayas eran de fino brocado, digo, que las sayas eran riquísimos faldellines de tabí de oro. Traían los cabellos sueltos por las espaldas, que en rubios podían competir con los rayos del mismo sol, los cuales se coronaban con dos guirnaldas de verde laurel y de rojo amaranto tejidas. La edad, al parecer, ni bajaba de los quince ni pasaba de los diez y ocho."30

Todo tiene su explicación, y se la dan puntualmente las dos cortesanas pastoras. Se lo cuentan así a Don Quijote y Sancho: "En una aldea que está hasta dos leguas de aquí, donde hay mucha gente principal y muchos hidalgos y ricos, entre muchos amigos y parientes, se concertó que con sus hijos, mujeres e hijas, vecinos, amigos y parientes, nos viniésemos a holgar a este sitio, que es uno se los más agradables de estos contornos, formando entre todos una nueva y pastoril Arcadia, vistiéndonos las doncellas de zagalas y los mancebos de pastores. Traemos estudiadas dos églogas, una del famoso poeta Garcilaso, y otra del excelentísimo Camoes..."31. Esto ocurre hacia el fin de la Segunda parte del libro. La intención era buena, y don Quijote se ofrece a los pretendidos pastores para proteger el espectáculo, y, con la novedad de reconocer al caballero que algunos habían leído sus aventuras de la Parte Primera del libro, ya impreso, don Quijote proclama por dos veces la defensa del lugar. Pero con lo pastoril no se puede jugar e interrumpir un camino real, pues en esto que llega por allí una conducción de toros, y los animales derriban sin reparos al pretendido justador, y lo dejan, como siempre, maltrecho y caído, ridículo pero no muerto. La farsa pastoril no va con don Quijote, pero es una forma de entretenimiento social que creó una Arcadia con los vecinos de una aldea, que, como los de las ciudades, participan de la literatura pastoril en algún grado de su expresión.

\section{INTERPRETACIÓN PASTORIL DE LAS BODAS DE CAMACHO}

Otro episodio del Quijote admite también una interpretación pastoril. En casa de don Diego de Miranda, unos labradores le informan que van a unas bodas, las de Camacho, y le ponen en antecedentes del caso. Camacho es un rico labrador que prepara su casamiento con la hermosa Quiteria, a la que también pretende Basilio desde niño, otro labrador que no tiene bienes de fortuna. Sólo el levísimo apoyo del título del capítulo XIX de esta Segunda Parte denuncia la condición pastoril del caso: "Donde se cuenta la aventura del pastor enamorado...", y que Basilio sea un "zagal", como se le llama en la presentación. No hay referencia a una "Arcadia" ni fingida ni contrahecha, y el ideario pastoril no se muestra tan patente. Es un caso que les sale al paso por los caminos en la

30. Quijote, II, cap. LVIII, págs.1100-1101.

31. Quijote, II, cap. LVIII, pág. 1101.

ANALES CERVANTINOS, VOL. XXXVII, PP. 15-32, 2005. ISSN: 0569-9878 
parte de España que recorren. Es su participación en "las mejores bodas y más ricas que hasta el día de hoy se habrán celebrado en la Mancha." 32 En la Galatea también se celebran bodas, las de Daranio y Silveria, y el infortunado Mileno sale rechazado, como luego se dirá, pero son motivo para reunirse los pastores, y allí sólo se plantean los casos del desdén, la ausencia y los celos, expuestos en versos. En el Quijote existe una boda aldeana, con desbordamiento de vecinos que no acuden para oír discursos sobre el amor, sino para comer las aves que cuelgan de los árboles y beber los sustanciosos caldos que cuecen bajo la fronda. Es un acierto de Cervantes reunir los dos planos de tensión: la tópica descripción del amanecer de la tradición antigua y la percepción del mundo de Sancho que, al despertarse, huele el aire: "a) Apenas la blanca aurora había dado lugar a que el luciente Febo con el ardor de sus calientes rayos las líquidas perlas de su cabello enjugase [el rocío], cuando don Quijote... b) ...despertó, en fin, soñoliento y perezoso [Sancho] y volviendo el rostro a todas partes, dijo: -De la parte desta enramada, sino me engaño, sale un tufo y olor más de torreznos asados que de juncos y tomillos; bodas que por tales olores comienzan, para mi santiguada que deben ser abundantes y generosas" 33 . El deslizamiento entre los planos a) y b) pudo ser una catástrofe. Con el de la aurora y sus tópicos vamos a dar en la Edad de Oro, pero la sensualidad de Sancho conduce al apetito primario. Sin embargo, las bodas no llegaron a celebrarse. El caso, en la Galatea, Cervantes había contado una anécdota diferente: Daranio, el rico, casa con Silveria, y Mileno, el pobre, se ausenta de la tierra, y deja la vía libre para el matrimonio pactado ${ }^{34}$.

Basilio, en el Quijote, no se conforma con la presión social de la riqueza, y entonces salva la situación a su favor con una artimaña propia de un pícaro. Hace como si se matara, hace correr la sangre de un animal muerto y, manchándose los vestidos, finge el suicidio por amor y como si estuviera a punto de una aparente muerte, logra que el cura lo case con Quiteria por compasión. Logrado esto, el avispado Basilio se levanta indemne, y todos gritan ante el suceso; “¡Milagro, milagro!”, pero él precisa: "No, milagro, milagro, sino industria, industria!". Excelente exclamación, a la medida de los tiempos. La industria, esto es, la habilidad, el ansia de lograr lo que se quiere, de buena o mala manera, domina por sobre las fuerzas sobrenaturales. La exclamación puede valer como signo de los tiempos. Acabaron los milagros, sean los religiosos o los del heroísmo, y mejor vale la industria propia de los avisados como Basilio. Los concurrentes se dividen en dos bandos enfrentados: el del justamente ofendido Camacho y sus amigos, con el engañado cura, y del artero Basilio. ¿Por quién se inclina don Quijote? Y considera el caso desde un curioso punto de vista económico. Camacho representa el poder de la riqueza, que puede comprar la hermosura y el gozo amoroso que la acompaña. Basilio es el pobre

32. Quijote, II, cap. XIX, pág. 782.

33. Quijote, II, cap. XX, pág. 790 y 791.

34. Galatea, edición citada, 1995, III, págs. 328-329. 
que sólo tiene el mérito del amor correspondido. Basilio no cede como Mileno en la Galatea, y su rebelión es la picardía, un ardid que le inspira el amor. Y entonces don Quijote se pone del lado de Basilio. y lo justifica así: "advertid que el amor y la guerra son una misma cosa, y así como en la guerra es cosa es cosa lícita y acostumbrada usar ardides y estratagemas para vencer al enemigo, así en las contiendas amorosas se tienen por buenos los embustes y marañas que se hacen para conseguir el fin que se desea, como no sean en menoscabo y deshonra de la cosa amada. Quiteria era de Basilio, y Basilio, de Quiteria, por justa y favorable decisión de los cielos. Camacho es rico y podrá comprar su gusto cuando, donde y como quisiere". ${ }^{5}$ He aquí que, en el caso de Marcela fue una cuestión metafísica de libertad, y aquí se cambia por las argucias por lograr la enamorada, asediada esta vez por el poder de la riqueza. La aventura de Marcela es de orden intelectual y trágico, y ocurre cuando aún don Quijote es caballero novicio. La disputada boda de Quiteria con Camacho y Basilio ocurre cuando don Quijote es un experimentado caballero (y observemos que sus nombres están al ras de la vida aldeana). El caballero se inclina por el lado del que se comportó como un pícaro. Y con ello corroboraba el dicho de Virgilio, tópico indestructible: "Omnia vincit Amor, et nos cedamos Amori" (Bucólicas, X, 69). Y además don Quijote impide el encuentro entre camachistas y basilianos, pues adivina que Camacho es un "pacífico", y se deja convencer de que lo ocurrido es lo mejor, y Basilio se marcha con la novia a su casa, y también invita a don Quijote ofreciéndole lo mejor que tiene. Y don Quijote tiene ocasión de decir esto, como consejo a Basilio: “...el de casarse los enamorados era el fin de más excelencia, advirtiendo que el mayor contrario que el amor tiene es la hambre y la continua necesidad; porque el amor es todo alegría, regocijo y contento, y más cuando el amante está en posesión de la cosa amada, contra quien son enemigos opuestos y declarados la necesidad y la pobreza".36

Cervantes partió de la burla del tópico de la aurora y ha dado en esta punzante reflexión en la que no es desacertado notar la resonancia de la experiencia del propio escritor.

\section{DON QUIJOTE, PASTOR}

Cerremos esta interpretación de la presencia de la materia pastoril en el Quijote con lo que era de esperar: la posible -y esperable- transformación del héroe que, una vez vencido, se convierte en pastor. Cuando vuelve derrotado a la aldea, imagina con Sancho hacerse pastor. Quien desvarió con los libros de caballerías, pudo hacerlo con otros, y más con los de pastores. Ya lo había previsto la sobrina de don Alonso. Esto dice sobre el asunto: "Bien los puede vuestra merced mandar quemar como a los demás, porque no sería mucho que,

35. Quijote, II, cap. XXI, pág. 207.

36. Quijote, II, cap. XXII, pág. 809 ,

anales CeRVANTINOS, VOL. XXXVII, PP. 15-32, 2005. ISSN: 0569-9878 
habiendo mi señor tío, sanado de la enfermedad caballeresca, leyendo estos, se le antojase de hacerse pastor y andarse por los bosques cantando y tañendo, y, lo que sería peor, hacerse poeta, que, según dicen, es enfermedad incurable y pegadiza." ${ }^{37}$ Alfa y omega del destino de una persona que se empeñó en ser personaje literario, y también testimonio de que Cervantes desde el comienzo del libro sostiene esta otra tensión de la pastoril hasta el fin del mismo, concertando esta armonía de los géneros literarios que confluyen en su obra.

Este episodio final ocurre cuando vuelve derrotado a la aldea, sin que pueda por un tiempo seguir como caballero andante. Se le ocurre que él, Sancho y los amigos podrían comportarse como los pastores de los libros. Incluso se anuncian los disfraces onomásticos: El pastor Quijotiz, Pancino, Curambro, Carrascón. Pero ya es tarde y la cordura, con su niebla razonable, invade el alma de don Alonso y llega pronto la muerte. El proceso de la quijotización pastoril indica que su desarrollo no sería posible en el mismo sentido que se había tratado la materia caballeresca. El escritor aún guardaba en su casa, probablemente en el estante de algún armario, la segunda parte de la Galatea, más o menos terminada. La literatura pastoril, propicia también al tratamiento burlesco, se salva en esta ocasión.

\section{Y, POR FIN, LA CONSIDERACIÓN BURLESCA EN LAS 'NOVELAS EJEMPLARES'}

La "novela", desde que Boccaccio le dio la primitiva fórmula europea, era más propicia a convenir con la experiencia humana como elemento literario. Es curiosa una observación de Lope de Vega, el gran autor teatral, metido también en afanes novelescos. Se dirige a Marcia Leonarda (su Marta de Nevares) en un párrafo de La más prudente venganza: "Ya se llegaba la hora del comer y ponían las mesas, para que sepa V.M. que no es esta novela libro de pastores, sino que han de comer y cenar todas las veces que se ofreciere ocasión..." 38 Lope escribe para Marcia Leonarda, una mujer que prefería los libros de pastores, y diferencia las dos especies narrativas. Cervantes necesita acudir a otro género literario, el del diálogo. Por eso es uno de sus diálogos el que se mezcla en la impresión de Las novelas ejemplares el que cumple esta misión (La novela y coloquio que pasó entre Cipión y Berganza). Y el diálogo lo es a través del convencionalismo de que ocurre entre perros, y de esta manera puede exponer el punto de vista del animal que lo desata del uso de la materia pastoril en su uso novelesco.

Así dice el perro Berganza, que oye leer a su ama, lectura en voz alta, lo siguiente: “...digo que en aquel silencio y soledad de mis siestas, entre otras

37. Quijote, I, cap. VI, pág.84.

38. Novelas a Marcia Leonarda, 
cosas, consideraba que no debía de ser verdad lo que había oído contar de la vida de los pastores; a lo menos, de aquellos que la dama de mi amo leía en unos libros cuando yo iba a su casa...". 39 Y desde su experiencia como perro que lo habría sido de pastores, reflexiona así: "Digo que todos los pensamientos que he dicho, y muchos más, me causaron ver los diferentes tratos y ejercicios que mis pastores [...] tenían de aquellos que había oído leer que tenían los pastores de los libros, porque si los míos cantaban no eran canciones acordadas y bien compuestas, sino un "Cata el lobo dó va, Juanica" y otras cosas semejantes; [...] y no con voces delicadas, sonoras y admirables, sino con voces roncas, que, solas o juntas, parecía, no que cantaban, sino que gritaban o gruñían [...]. Por donde vine a entender [...] que todos aquellos libros son cosas soñadas y bien escritas para entretenimiento de los ociosos, y no verdad alguna, que a serlo, entre mis pastores hubiera alguna reliquia de aquella felicísima vida, y de aquellos prados, espaciosas selvas, sagrados montes, hermosos jardines...".

Y ahora viene lo que es decisivo para el género literario. En cuanto el perro ha penetrado en la contextura pastoril, el mismo perro está al punto de caer en el encanto del género, y entonces dice: "...se me iba calentando la boca, que no parara hasta pintarte un libro entero de estos que me tenían engañado."40

En el Quijote se encuentran acomodadas en su lugar conveniente las diferentes formas genéricas de la materia pastoril. Y actúan los elementos de la creación literaria que le es propia para lograr con su integración el portentoso encanto de la obra.

Y aquí lo dejamos. ¡Si hasta la conciencia razonablemente perruna de Berganza hace que sienta la llamada incontenible de escribir a la manera de un libro de pastores! Y esto también justifica literaria y humanamente que Cervantes hubiese escrito la primera parte de la Galatea (y tuviese hasta la hora de la muerte el cuidado de continuarla). Y también que fuese a parar en ese río ancho y caudaloso que es el Quijote, el entresijo vital de Cervantes y de sus contemporáneos. Es un caso más del vaivén entre "persona", en la plenitud de su significado, y el "personaje", figura de ficción imaginada. Es la pendulación entre la inexorable realidad y su interpretación poética, creadora mediante el lenguaje. Ese es, ni más ni menos, el quehacer del escritor, y lo fue de manera ejemplar en Cervantes.

39. Cervantes, Novelas Ejemplares, III, edición de Juan bautista Avalle Arce, Clásicos Castalia, Madrid, 1982, Coloquio de los perros, pág. 251.

40. Novelas Ejemplares, obra citada, III, pág 254-255. 


\section{BIBLIOGRAFÍA}

Arellano, Ignacio, "Cervantes en Calderón”, Anales Cervantinos, XXXV, 1999, págs. 9-35. Avalle-ArCE, Juan Bautista, La novela pastoril española, Madrid, Istmo, 1974, $2^{\text {a }}$ edición. Blecua Teijeiro, José Manuel, "Garcilaso y Cervantes", Homenaje a Cervantes, Madrid, Ínsula, 1948, págs, 141-150.

Canavaggio, Jean, Cervantes, Madrid, Espasa Calpe, 1987.

Cervantes, Miguel de. Don Quijote de la Mancha, Barcelona, Instituto Cervantes. Crítica, 1998, 2 tomos.

Idem, La Galatea, Madrid, Cátedra, Letras Hispánicas, vol. 389, 1995.

Cervantes and the Pastoral, Cleveland, Pennstate University-Behrend College, Cleveland State University, 1986.

Damiani, Bruno y Barbara MUJICA, "Et in Arcadia ego". Essais on Death in the Pastoral Novel”, Lanham University, University Press of America, 1990.

FERRI. José María, "Don Quijote: ¿burlón o melancólico?, Cervantes y su mundo, II. Estudios de Literatura 91, Kassel, Edition Reichenberger, 2005, págs. 157-176.

Finello, Dominic, "The Pastoral Novel and Spain's Literary Culture of the Early Seventeeth Century", A Celebration of Brooklyn Hispanism, Juan de la Cuesta, 2004, págs. 77-94.

Idem, "Las dos Arcadias del Quijote", Cervantes y su mundo. II Estudios de Literatura 91, Kassel, Edition Reichenberger, 2005, págs. 177-192.

Iventosch, Herman, "Cervantes and courtly love: the Grisóstomo-Marcela episode", Publications of the Modern Language Association of America, 89, 1974, págs. 64-76.

Idem, "Dulcinea, nombre pastoril", Nueva Revista de Filología Hispánica, 17, 1964, págs. 60-81.

LAPESA, Rafael, “Aldonza-Dulce-Dulcinea”, De la Edad Media a nuestros días, Madrid, Gredos, 1967, págs. 212-218.

López Estrada, Francisco, "Estudio crítico de La Galatea de Cervantes", La Laguna de Tenerife, Universidad, 1948.

Idem, Los libros de pastores en la literatura española, Madrid, Gredos, 1974.

Idem y Huerta CAlvo, Javier, y Infantes de Miguel,Víctor, Bibliografía de los libros de pastores en la literatura española, Madrid, Universidad Complutense,1984.

Márquez Villanueva, Francisco, "Amantes en Sierra Morena”, Personajes y temas del "Quijote", Madrid, Taurus, 1975, págs, 15-75.

PÉREZ, Joseph, "La pastorale", Homenaje a Hans Flasche, Sttutgart, F, Steiner, 1991, págs. 371-378.

REDONDO, Augustin, "El personaje de don Quijote: tradiciones folklórico-literarias, contexto histórico y elaboración cervantina”, Nueva Revista de Filología Hispánica, 29, 1980, págs. 36-50.

Idem, "La tradición carnavalesca en el Quijote", Formas carnavalescas en el arte y la literatura, Barcelona, Ediciones del Serbal, 1989, págs. 133-181.

Rivers, Elías L., "Cervantes y Garcilaso", Homenaje a José Manuel Blecua, Madrid, Gredos, págs. 565-570.

Sieber, Harry, "Society and the Pastoral Vision in the Marcela-Grisóstomo Episode of Don Quixote", Estudios literarios de hispanistas norteamericanos dedicados a Helmut Hatzfeld con motivo de su ochenta aniversario, Barcelona, Hispam., 1974, págs. 185-194.

StaAG, Geoffrey, "Revision in Don Quixote, part I", Hispanic Studies in Honor of I. González-Llubera, Oxford, Dolphin Book, 1959, págs. 347-366.

Urbina, Eduardo, El sin par Sancho Panza: parodia y creación, Barcelona, Anthropos, 1991. 


\title{
Resumen
}

En el Quijote un hidalgo de la Mancha pierde el juicio por leer libros de caballerías e imitar las aventuras que cuenta esta literatura. Lee también libros de pastores, pero los pastores existen en su realidad social y es un oficio de las gentes del campo. Sancho declara haber sido pastor. La poesía de Garcilaso atrae a su señor don Quijote, y en una ocasión se la muestra en prosa a Sancho. Dulcinea es el nombre que da don Quijote a su amor, y parece nombre de pastora. Unos cabreros oyen un discurso pastoril que les dirige don Quijote. Y unos pastores lo acercan a Sierra Morena al entierro de Grisóstomo, que ha muerto de amor por Marcela. También asiste a la preparación de las bodas de Camacho, un rico pastor, y ayuda a que la novia se case con Basilio, un pastor pobre. Finalmente, don Quijote es derrotado como caballero por un amigo que quiere que se retire a la aldea. Obligado a regresar a su casa por un acuerdo con el que lo ha vencido, entonces él y sus amigos y vecinos, se preparan para vivir a la manera pastoril, y el hidalgo recobra la razón, y así muere cuerda y cristianamente.

Palabras clave: Ficción caballeresca y pastoril. Géneros literarios implicados. Fábula. Novela. Poesía y prosa pastoriles. Pastores. Arcadia. Amor pastoril y amor platónico.

\begin{abstract}
Alonso Quijano become to be don Quixote, when the reading of some books of knigtherrantry makes him mad. But don Alonso reads also pastoral literature. Sancho confess the was a rustician shepherd. Dulcinea is a name nearly to the pastoral literature. Don Quixote pronounces a pastoral lecture, adressed to others shepherds. In Sierra Morena, during the Grisóstomo's funeral, Marcela enunciate \& discourse in favor of love liberty. Don Quixote attends to Camacho's wedding and he intervenes in the facts of this act. Finally, Don Quixote regains his mind, and he dies like a christianman being Alonso Quijano.
\end{abstract}

Key word: Knigth-errantry and pastoral Fiction. Genre. Novel. "Roman”. Pastoral Poetry and Prose. Shepherds. Chivalrous. Books of Knigt-errantry. 